\title{
Diurnal variation of short-period (20-120 min) gravity waves in the equatorial Mesosphere and Lower Thermosphere and its relation to deep tropical convection
}

\author{
N. Venkateswara Rao ${ }^{1}$, Y. Shibagaki ${ }^{2}$, and T. Tsuda ${ }^{1}$ \\ ${ }^{1}$ Research Institute for Sustainable Humanosphere, Kyoto University, Uji, Japan \\ ${ }^{2}$ Faculty of Information and Communication Engineering, Osaka Electro-Communication University, Neyagawa, Japan \\ Received: 9 February 2011 - Revised: 15 March 2011 - Accepted: 17 March 2011 - Published: 1 April 2011
}

\begin{abstract}
We study short period gravity waves (20-120 min) in the equatorial Mesosphere and Lower Thermosphere (MLT) using a Medium Frequency (MF) radar at Pameungpeuk $\left(7.4^{\circ} \mathrm{S}, 107.4^{\circ} \mathrm{E}\right)$, Indonesia. In particular, we study local time and seasonal variation of the gravity wave variance and its relation to tropical convection. The gravity wave variance at $88 \mathrm{~km}$ enhances between 20:00 LT and 07:00 LT, with a peak at 02:00-03:00 LT. The enhancement is mainly observed during February-April and September-October and shows inter-annual variability. Convective activity over the same location persists from 16:00-21:00 LT with a peak activity $\sim 18: 00 \mathrm{LT}$ and enhances between November-April. Time delay between the peak of convection and that of gravity wave activity ranges $1-15 \mathrm{~h}$, which is consistent with theoretical calculations and previous reports based on reverse ray tracing analysis.
\end{abstract}

Keywords. Meteorology and atmospheric dynamics (Convective processes; Middle atmosphere dynamics; Waves and tides)

\section{Introduction}

It has long been thought that convection in the tropics is an important source for gravity waves (GWs) observed in the equatorial Mesosphere and Lower Thermosphere (MLT) region. These convectively generated GWs in the troposphere propagate into the middle atmosphere and deposit their energy and momentum and thus modify the global circulation of the middle atmosphere. Especially, the Indonesian Maritime Continent (IMC) is one of the most convectively active regions and hence the equatorial MLT region above IMC is believed to be rich in GWs.
Convection generates GWs throughout the full range of phase speeds, wave periods, and vertical and horizontal scales (Fritts and Alexander, 2003). Among the spectrum of GWs, the long-period GWs propagate at small elevation angles and hence may be observed in the MLT region at large horizontal distances from the convective sources, making correlation with clouds or other indicators of convection more difficult (Fritts and Alexander, 2003; Ratnam et al., 2009). The short-period GWs, on the other hand, are believed to propagate nearly vertically up from the convective source and hence are anticipated to correlate well with the convective sources below. Further, it is this part of the GW spectrum that is believed to carry a majority of the momentum flux to the MLT region (Fritts et al., 1990).

Relation between convection and GWs have been observed in the troposphere and lower stratosphere (e.g. Dutta et al., 2009; Alexander et al., 2008b) and in the MLT region (e.g. Kovalam et al., 2006; Taylor et al., 2009). Studies using GPS Radio Occultation data also showed relation between convection and GWs observed in the troposphere and lower stratosphere (Tsuda et al., 2000; Alexander et al., 2008a). Simulation and modeling studies much advanced our understanding on the convective generation of GWs (e.g. Piani et al., 2000) and their propagation to the stratosphere and MLT region (Alexander, 1996). Reverse ray tracing analysis also confirmed that convection is the main source for at least some of the GWs observed in the MLT region (Vadas et al., 2009).

In this paper, we study the diurnal, seasonal and interannual variability of short period $(20-120 \mathrm{~min}) \mathrm{GWs}$ in the MLT region over Pameungpeuk $\left(7.4^{\circ} \mathrm{S}, 107.4^{\circ} \mathrm{E}\right)$, Indonesia and their possible relation to the tropical convection in the troposphere.

Correspondence to:

N. Venkateswara Rao

(ionovenki@gmail.com)

Published by Copernicus Publications on behalf of the European Geosciences Union. 

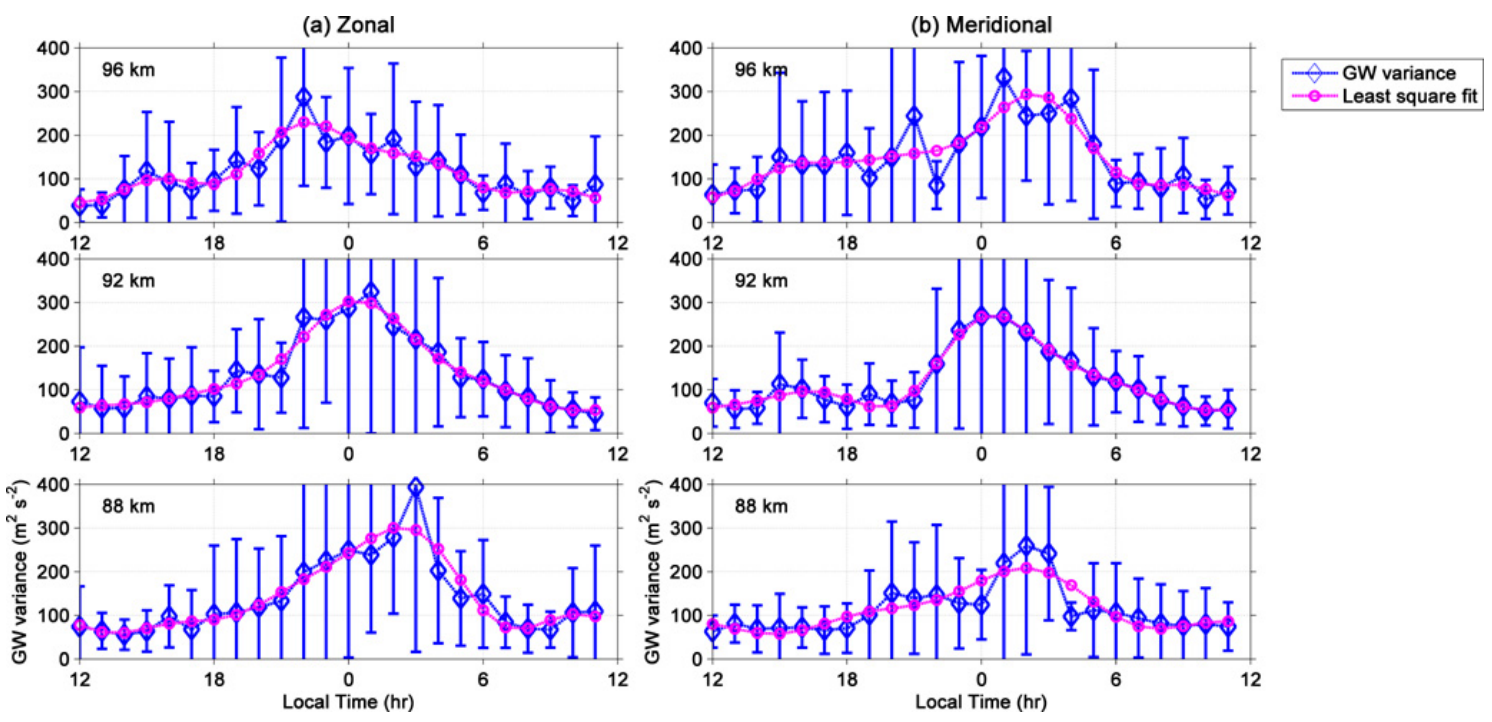

Fig. 1. Diurnal variation of 20-120 min GW variance averaged from 1-31 March 2008 for (a) zonal, and (b) meridional components at heights of $96 \mathrm{~km}, 92 \mathrm{~km}$, and $88 \mathrm{~km}$ (from top to bottom). The over plotted magenta line in each panel represents least square fit by considering the diurnal, semi-, ter- and quarter-diurnal cycles.

\section{Observations and data}

The MLT wind data used in this study were acquired using a Medium Frequency (MF) radar located at Pameungpeuk $\left(7.4^{\circ} \mathrm{S}, 107.4^{\circ} \mathrm{E}\right)$, Indonesia. This radar is operating at a frequency of $2.008 \mathrm{MHz}$ and measures winds using the spaced antenna technique in the height range of $78-98 \mathrm{~km}$ with resolutions of $2 \mathrm{~km}$ in height and $2 \mathrm{~min}$ in time. The data acceptance rate is highest at $\sim 88 \mathrm{~km}$. In the present study, we use the data collected from March 2004 to 30 September 2010. Major data gaps exist during 10 August 2004 to 6 November 2004, and 13 February 2007 to 2 October 2007.

The horizontal winds data acquired by the MF radar are averaged to get $10 \mathrm{~min}$ interval data. A block of three hours (which contains 18 data points), sliding forward by one hour, is used to estimate the variance of $20-120 \mathrm{~min}$ period GWs. Each three-hour block is then subjected to high pass filtering with a cutoff of $120 \mathrm{~min}$. The estimated GW variance for each block is attributed to the middle of the three hour interval. Thus, we obtained hourly values of GW variance which are used to study the diurnal variation.

We use the cloud-top equivalent black body temperature (TBB) data as a proxy for deep tropical convection (Nitta and Sekine, 1994). Low and high temperatures indicate high and low clouds, respectively. We used hourly values of TBB in the average area of $7.15^{\circ} \mathrm{S}$ to $7.65^{\circ} \mathrm{S}$ and $107.15^{\circ} \mathrm{E}$ to $107.65^{\circ} \mathrm{E}$, which is close to Pameungpeuk.

\section{Results}

\subsection{Diurnal variation of $\mathrm{GW}$ variance}

Diurnal variation of the GW variance averaged for March 2008 is shown in Fig. 1a and $b$ for the zonal and meridional components, respectively. The three panels in each figure correspond to heights of $96 \mathrm{~km}$ (top panel), $92 \mathrm{~km}$ (middle panel), and $88 \mathrm{~km}$ (bottom panel). The GW variance at $88 \mathrm{~km}$ starts to increase from 21:00 LT and reaches its peak around 03:00 LT and then decreases. The local time of peak GW variance precedes with height, the peak being at 03:00 LT at $88 \mathrm{~km}$ and at $22: 00 \mathrm{LT}$ at $96 \mathrm{~km}$. This is more prominent in the zonal component. The maximum mean variance is $\sim 300 \mathrm{~m}^{2} \mathrm{~s}^{-2}$. The dashed line with closed circles represents the least square fitting by considering the diurnal, semi-, ter-, and quarter-diurnal cycles of the mean $\mathrm{GW}$ variance. The fitted line converges well with the mean variance indicating that there could be a possibility of interaction between tides and GWs. Further evidence for this interaction comes from the phase of the diurnal component which precede with height, especially in the zonal component. Amplitudes and phases of the fitted diurnal and semidiurnal cycles, shown in Table 1, indicate that they contribute to most of the observed local time variation of the GW variance. This aspect is more clearly discussed in later sections. 
Table 1. Amplitudes and phases of diurnal and semidiurnal cycles of GW variance.

\begin{tabular}{|c|c|c|c|c|c|c|c|c|c|c|}
\hline \multirow{3}{*}{$\begin{array}{c}\text { Height } \\
(\mathrm{km})\end{array}$} & \multicolumn{2}{|c|}{ Mean } & \multicolumn{4}{|c|}{ Diurnal cycle of GW variance } & \multicolumn{4}{|c|}{ Semidiurnal cycle of GW variance } \\
\hline & \multirow{2}{*}{$\begin{array}{c}\text { Zonal } \\
\left(\mathrm{m}^{2} \mathrm{~s}^{-2}\right)\end{array}$} & \multirow{2}{*}{$\begin{array}{c}\text { Meridional } \\
\left(\mathrm{m}^{2} \mathrm{~s}^{-2}\right)\end{array}$} & \multicolumn{2}{|c|}{ Zonal } & \multicolumn{2}{|c|}{ Meridional } & \multicolumn{2}{|c|}{ Zonal } & \multicolumn{2}{|c|}{ Meridional } \\
\hline & & & $\begin{array}{l}\text { Amplitude } \\
\left(\mathrm{m}^{2} \mathrm{~s}^{-2}\right)\end{array}$ & $\begin{array}{l}\text { Phase } \\
\text { (h) }\end{array}$ & $\begin{array}{l}\text { Amplitude } \\
\left(\mathrm{m}^{2} \mathrm{~s}^{-2}\right)\end{array}$ & $\begin{array}{c}\text { Phase } \\
\text { (h) }\end{array}$ & $\begin{array}{l}\text { Amplitude } \\
\left(\mathrm{m}^{2} \mathrm{~s}^{-2}\right)\end{array}$ & $\begin{array}{c}\text { Phase } \\
\text { (h) }\end{array}$ & $\begin{array}{l}\text { Amplitude } \\
\left(\mathrm{m}^{2} \mathrm{~s}^{-2}\right)\end{array}$ & $\begin{array}{c}\text { Phase } \\
\text { (h) }\end{array}$ \\
\hline 96 & 117 & 148 & 71 & 23 & 82 & 24.5 & 19 & 11.1 & 42 & 2.7 \\
\hline 92 & 137 & 120 & 105 & 24.4 & 79 & 25 & 37 & 0.7 & 44 & 1.4 \\
\hline 88 & 141 & 113 & 98 & 25.3 & 60 & 25 & 42 & 1.5 & 21 & 1.3 \\
\hline
\end{tabular}
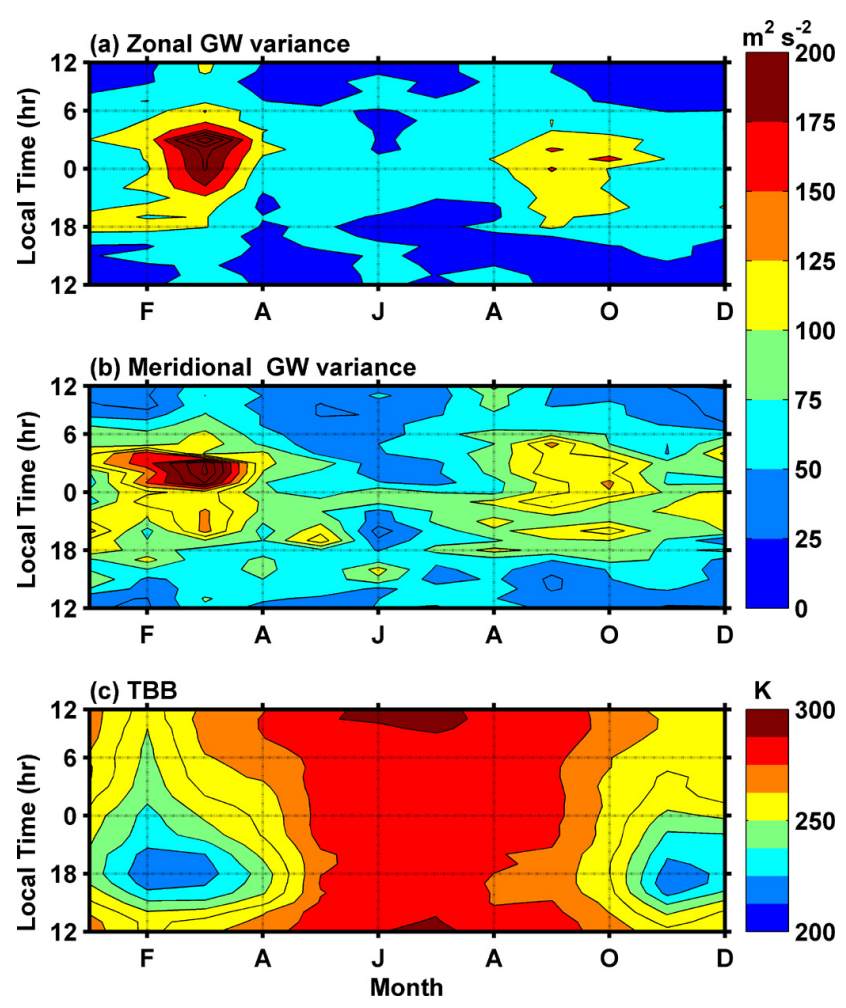

Fig. 2. Height-month contours of monthly mean values of (a) zonal component of 20-120 min GW variance, (b) meridional component of 20-120 min GW variance for $88 \mathrm{~km}$, and (c) cloud-top equivalent black body temperature (TBB).

\subsection{Relation between GW variance and convective activity}

\subsubsection{For the year 2008}

Figure $2 \mathrm{a}-\mathrm{c}$ shows the month-local time contours of monthly mean $\mathrm{GW}$ variance for the zonal and meridional winds at $88 \mathrm{~km}$, and TBB, respectively, for the year 2008 . $\mathrm{TBB}<230 \mathrm{~K}$ is generally considered to represent deep convection (e.g. Nitta and Sekine, 1994). Because the values presented here are monthly mean values, we consider
$\mathrm{TBB}<250 \mathrm{~K}$ as an indication of strong convection. The zonal component of the GW variance in Fig. 2a shows enhancement during February to April and during September to October, which exhibits nearly semiannual variation. Maximum value of GW variance is $\sim 390 \mathrm{~m}^{2} \mathrm{~s}^{-2}$ observed in March. The meridional component, shown in Fig. 2b, enhances during January to April and from August to October. Further, there is also some enhancement during November-December with GW variance reaching a maximum of $120 \mathrm{~m}^{2} \mathrm{~s}^{-2}$. The maximum value is $\sim 250 \mathrm{~m}^{2} \mathrm{~s}^{-2}$ observed in March. Thus, a semiannual variation is clearly observed in both the zonal and meridional component.

The TBB in Fig. 2c shows low values $(<230 \mathrm{~K})$ during February to March and from November to December. $\mathrm{TBB}<250 \mathrm{~K}$ is observed from January to April and from late October to December. Thus, the seasonal variation of $\mathrm{GW}$ variance correlates well with that of convection during February to April and doesn't correlate during SeptemberOctober. Further, corresponding to deep convection during November-December there is no enhancement of the GW activity, especially in the zonal component.

Coming to the local time variation, the GW variance enhances between 18:00 LT and 06:00 LT with peak variance at $02: 00 \mathrm{LT}$ having values $>200 \mathrm{~m}^{2} \mathrm{~s}^{-2}$. Further, there is also a slight enhancement after 06:00 LT in the meridional component with GW variance going to $75-100 \mathrm{~m}^{2} \mathrm{~s}^{-2}$. Deep convection is observed during 14:00-24:00 LT with peak at 18:00 LT. Thus, there is $\sim 8 \mathrm{~h}$ time delay between the peak of convective activity and the peak of GW enhancement.

\subsubsection{Inter-annual variability from 2004 to 2010}

Figure 3 shows the month-LT contour maps at $88 \mathrm{~km}$, similar to Fig. 2, but for all years from 2004 to 2010. Solid lines in between show starting of the year. The background GW variance in all years is $<75 \mathrm{~m}^{2} \mathrm{~s}^{-2}$. Further, the GW variance is less during daytime $\left(<75 \mathrm{~m}^{2} \mathrm{~s}^{-2}\right)$ and enhances from evening to morning hours. The enhanced $\mathrm{GW}$ variance is sometimes $>200 \mathrm{~m}^{2} \mathrm{~s}^{-2}$. Between 2004 and 2006 the GW variance is less and lies in the range of $50-70 \mathrm{~m}^{2} \mathrm{~s}^{-2}$, close to the background values, except in February 2006 where it reached $150-175 \mathrm{~m}^{2} \mathrm{~s}^{-2}$. The GW variance is comparatively 


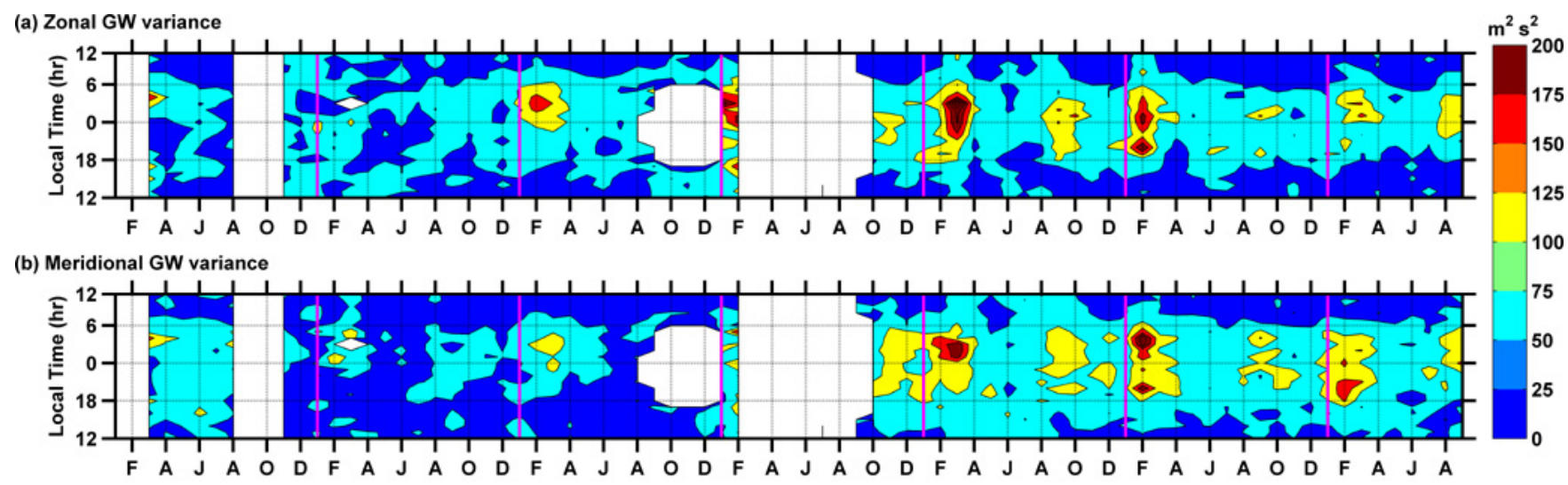

(c) TBB

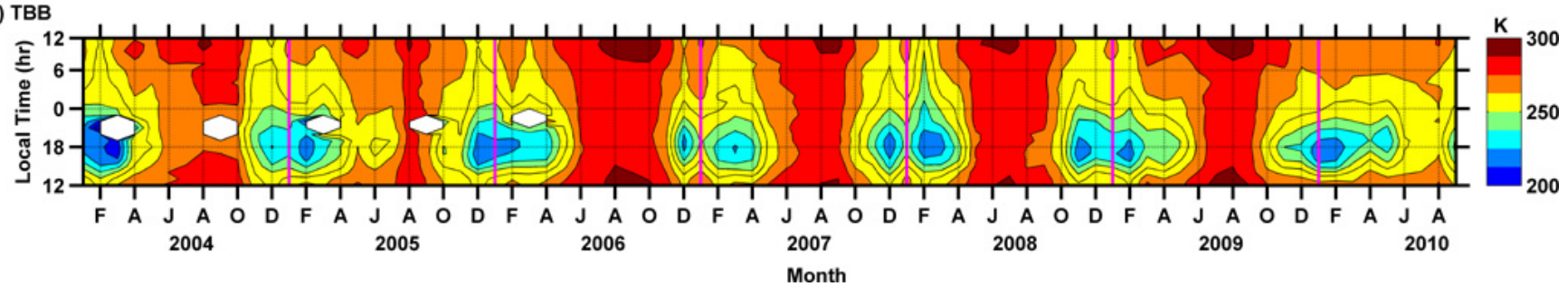

Fig. 3. Same as Fig. 2, but for all years from 2004-2010. Vertical lines are to separate the years.
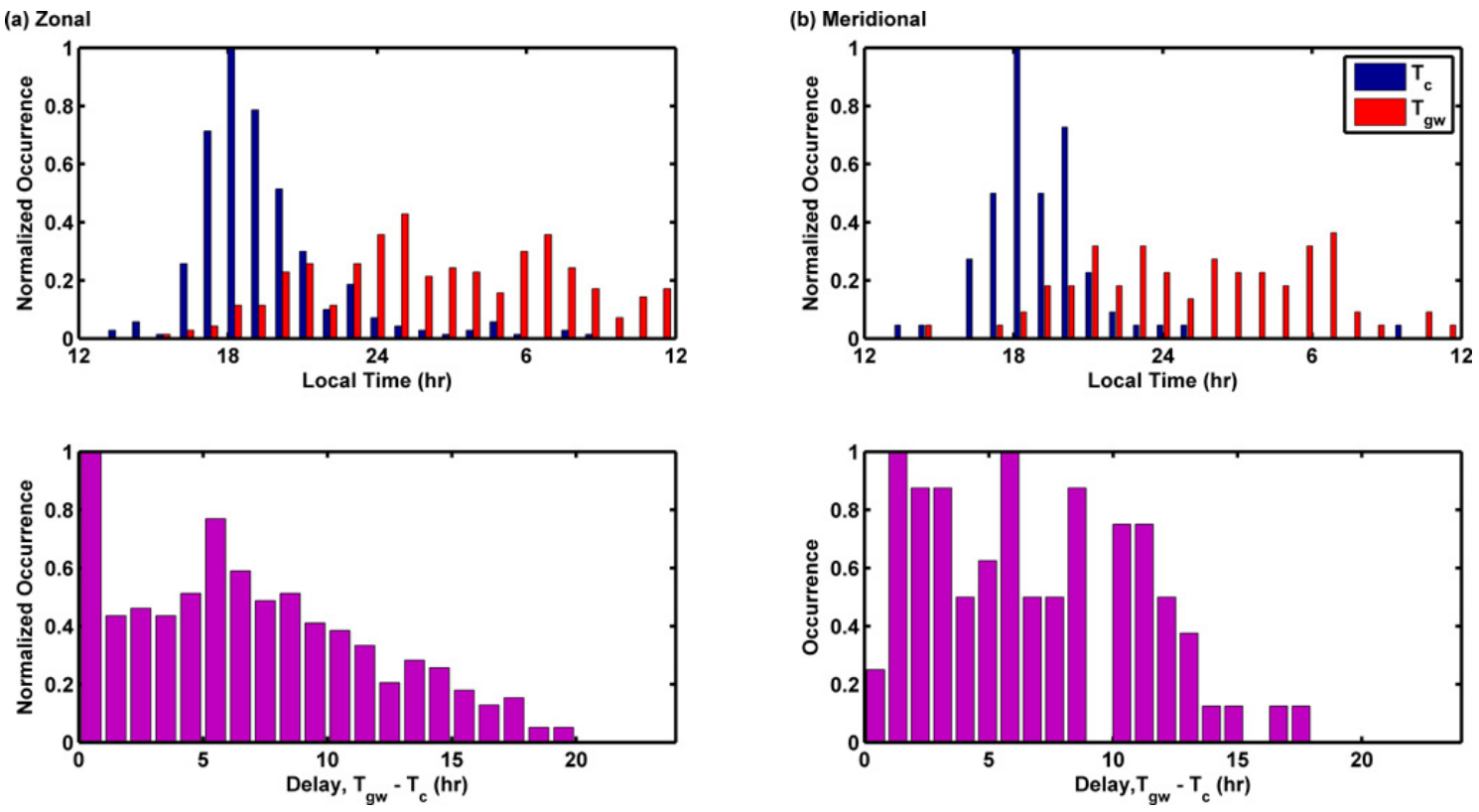

Fig. 4. Time of peak convective activity $\left(T_{\mathrm{c}}\right)$ and time of peak of $\mathrm{GW}$ variance $\left(T_{\mathrm{gw}}\right)$ (top panels) and difference between the $T_{\mathrm{gw}}$ and $T_{\mathrm{c}}$ (bottom panels) for (a) zonal and (b) meridional components, respectively.

larger in the beginning of 2007, before the data gap. Between October 2007 and September 2010, the GW variance during equinoxes is larger compared to that of previous years and reaches a maximum value of $>200 \mathrm{~m}^{2} \mathrm{~s}^{-2}$. During 20082010, the seasonal variability is similar in all years with GW enhancement during equinoxes. Further, the spring equinox enhancement is more than the autumn equinox.
The convective activity in Fig. 3c enhances from November to April of every year. During this period, strong convection with $\mathrm{TBB}<250 \mathrm{~K}$ is observed during 14:00-01:00 LT in every year. Deep convection with $\mathrm{TBB}<230 \mathrm{~K}$ also exists between 17:00 and 20:00 LT. The seasonal variation of GW activity and convection is similar to 2008, except some inter-annual variability in the former. 


\subsection{Time delay between peaks of tropical convection and $G W$ variance}

Figure $4 \mathrm{a}$ and $\mathrm{b}$ represents the local time of peak of the convection and that of the GW variance (top panels) and delay between peaks of the two (bottom panels) for the zonal and meridional components, respectively. Data from January to March of all years are considered for this analysis. A criterion of $\mathrm{TBB}<230 \mathrm{~K}$ limits the total number of cases to 79 . From Figs. 3 and 4, we can note that the convection mostly starts after 12:00 LT and the GW variance after 18:00 LT. Accordingly, we considered a $24 \mathrm{~h}$ dataset, from 12:00 LT of a day to 12:00 LT of the next day. From this $24 \mathrm{~h}$ dataset, convective activity peak (minimum value of TBB) is identified first and its local time $\left(T_{\mathrm{c}}\right)$ is noted. Since the GW activity is supposed to peak after the convective activity, the local time of peak GW activity is studied between $T_{\mathrm{c}}$ and 12:00 LT of next day. From this interval the local time of peak GW variance $\left(T_{\mathrm{gw}}\right)$ is obtained. This analysis is carried out to all the 79 datasets. Then $T_{\mathrm{c}}$ and $T_{\mathrm{gw}}$ are plotted as histograms and shown in the top panels of Fig. 4a and b. The difference between the $T_{\mathrm{gw}}$ and $T_{\mathrm{c}}\left(T_{\mathrm{gw}}-T_{\mathrm{c}}\right)$ is shown in the bottom panels.

Top panels of Fig. $4 \mathrm{a}$ and $\mathrm{b}$ clearly reveal that the convective activity enhances between 16:00-21:00 LT with peak activity at 18:00 LT. GW activity shows enhancement from 20:00-07:00 LT with peak activity at 02:00-03:00 LT. Further, the enhanced convective activity persists for $\sim 6 \mathrm{~h}$ (16:00-21:00 LT) whereas the GW activity shows enhancement from 18:00 to 07:00 LT. Bottom panels of Fig. 4a and b quantify the actual time delay between the peaks of convective activity and GW variance. The delay is generally between $1-15 \mathrm{~h}$.

\section{Discussion}

The short period (20-120 min) GW variance shows a clear diurnal variation with enhanced activity during 20:0007:00 LT and nearly semiannual variability with primary peak during February-April and secondary peak during September-October. Previous studies in the equatorial and low-latitude MLT region also reveal such a semiannual variation of GW activity with peak during equinoxes (Sridharan and SatishKumar, 2008; Clemesha et al., 2009).

The convective activity over Pameungpeuk enhances from 14:00-24:00 LT and is maximum during November to April. Nitta and Sekine (1994) showed that the sea-land contrast enforces the diurnal variation in convective activity with maximum during the afternoon to evening hours over land and from midnight to morning over ocean. Further, Renggono et al. (2001) showed that the peak convective activity occurs during 13:00-21:00 LT at Serpong $\left(6.4^{\circ} \mathrm{S}, 106.7^{\circ} \mathrm{E}\right)$ and Bukittinggi $\left(0.2^{\circ} \mathrm{S}, 100.3^{\circ} \mathrm{E}\right)$, Indonesia. Thus, the di- urnal variation of convection in the present study is in accordance with the previous studies.

Further, the present study also shows that the time delay between the peak of convection and that of GW activity is 115 h. Linear GW theory (e.g. Eq. 25 of Fritts and Alexander, 2003) shows that for 20 (120) min GWs with a vertical wavelength of $10 \mathrm{~km}$ and a horizontal wavelength of $100 \mathrm{~km}$, the time required to travel $80 \mathrm{~km}$ is $\sim 2.7(\sim 16.5) \mathrm{h}$. For $5 \mathrm{~km}$ vertical wavelength it becomes $\sim 5.3(\sim 32) \mathrm{h}$. Further, reverse ray tracing analysis of Vadas et al. (2009) showed that the convective sources are located $140-1400 \mathrm{~km}$ away from the GW observation site. The GWs may take up to $18 \mathrm{~h}$ to travel from the convective source to the MLT region of the observation location.

For the GW enhancement during September-October, there is no corresponding convective activity over Pameungpeuk. Further, when there is enhancement in convective activity during November-December, there is no enhancement in the GW activity. This kind of mismatch can be explained by considering that the convective source locations are away from the observational site. Thus, it is possible that the convective activity during September to October is peaking at some other locations, somewhat far away from Pameungpeuk, and the GWs generated there propagate towards the Pameungpeuk. Similarly, the convective activity during November-December generates GWs that propagate away from the source location (in this case, Pameungpeuk) and hence they are not observed in the MLT region over Pameungpeuk. Nakamura et al. (2003) have shown that the origin of the short period GWs they observed was in the northern side of their observational site and hence they observed the GWs propagating towards south for most of the time.

Since we do not know exact locations of the convective sources generating GWs, we considered the convection over Pameungpeuk as a representative source for the GWs observed in the MLT region. We also tried to average the TBB over a certain latitude and longitude grid to verify if it better correlates with the GW variability. But as the averaged grid size increases, instead of giving a better picture, the local time and seasonal features of TBB are disappearing. Thus, exact locations of convective sources are required to clearly explain the diurnal and seasonal variations GW activity and to calculate the exact time delay.

There is also a possibility of wind filtering of the GWs by wave-mean flow interaction due to the underlying quasi biennial oscillation (QBO) and the stratospheric semiannual oscillation (SSAO) (e.g. Alexander et al., 2008a; Fritts and Alexander, 2003). These two oscillations can filter some portion of the GW spectrum, depending on the phase and amplitude of the oscillations and the phase speeds and propagation directions of the GWs, and might be responsible for the observed seasonal and inter-annual variability of the GW activity. However, the short period GWs seem to be less influenced by the wind filtering due to their large phase speeds. 
This study also showed that the diurnal and semidiurnal cycles of the GW variance account for most of the observed local time variation of the GW variance. Further, the phase of the diurnal component of the GW variance precedes with height. These indicate the possibility of interaction between the tides and GWs (Fritts and Vincent, 1987). Thus, the tidalGW interaction also needs to be critically examined at Pameungpeuk to understand the intriguing nature of the GW variability in the MLT region over Pameungpeuk.

\section{Conclusions}

We studied the diurnal variation of short period (20-120 min) GW variance from March 2004 to August 2010 using MF radar observations of horizontal winds over Pameungpeuk $\left(7.4^{\circ} \mathrm{S}, 107.4^{\circ} \mathrm{E}\right)$. To understand the diurnal, seasonal, and inter-annual variability of GW variance, we also studied the convective activity in the troposphere above Pameungpeuk. The important results of this study are (1) short period GWs show clear diurnal variation with enhanced activity during 20:00-07:00 LT; (2) GW activity shows nearly semiannual variation with stronger peaks during February-April and a secondary peak during September-October; (3) GW activity shows inter-annual variability being stronger during 20082010 compared to 2004-2006; (4) the convective activity over Pameungpeuk, traced through TBB, enhances (low values of TBB) from 14:00-24:00 LT; (5) convective activity is maximum during November to April; (6) enhancement in $\mathrm{GW}$ activity during spring equinox coincides well with the convective activity where as the peak in autumn does not; (7) the time delay between the peak convective activity and peak GW activity in the MLT region ranges from $1-15 \mathrm{~h}$. Characterization of GW activity in terms of diurnal and seasonal variability helps better handling them in the general circulation models.

Acknowledgements. The work of N. Venkateswara Rao was supported by the Japan Society for the Promotion of Science (JSPS) foundation (ID No: P09232). The Pameungpeuk MF radar is operated as a collaborative project between RISH and LAPAN. This study was supported in part by the Japanese Ministry of Education, Culture, Sports, Science and Technology (MEXT) through Grantsin-Aid for Scientific Research (19403009 and 22253006). The TBB data were provided by the Japan Meteorological Agency (JMA) through Kochi University, Japan.

Topical Editor C. Jacobi thanks one anonymous referee for her/his help in evaluating this paper.

\section{References}

Alexander, M. J.: A simulated spectrum of convectively generated gravity waves: Propagation from the tropopause to the mesopause and effects on the middle atmosphere, J. Geophys. Res., 101(D1), 1571-1588, 1996.
Alexander, S. P., Tsuda, T., Kawatani, Y., and Takahashi, M.: Global distribution of atmospheric waves in the equatorial upper troposphere and lower stratosphere: COSMIC observations of wave mean flow interactions, J. Geophys. Res., 113, D24115, doi:10.1029/2008JD010039, 2008a.

Alexander, S. P., Tsuda, T., Shibagaki, Y., and Kozu, T.: Seasonal gravity wave activity observed with the Equatorial Atmosphere Radar and its relation to rainfall information from the Tropical Rainfall Measuring Mission, J. Geophys. Res., 113, D02104, doi:10.1029/2007JD008777, 2008b.

Clemesha, B. R., Batista, P. P., Buriti da Costa, R. A., and Schuch, N.: Seasonal variations in gravity wave activity at three locations in Brazil, Ann. Geophys., 27, 1059-1065, doi:10.5194/angeo27-1059-2009, 2009.

Dutta, G., Ajay Kumar, M. C., Vinay Kumar, P., Venkat Ratnam, M., Chandrashekar, M., Shibagaki, Y., Salauddin, M., and Basha, H. A.: Characteristics of high-frequency gravity waves generated by tropical deep convection: Case studies, J. Geophys. Res., 114, D18109, doi:10.1029/2008JD011332, 2009.

Fritts, D. C. and Alexander, M. J.: Gravity wave dynamics and effects in the middle atmosphere, Rev. Geophys., 41(1), 1003, doi:10.1029/2001RG000106, 2003.

Fritts, D. C. and Vincent, R. A.: Mesospheric momentum flux studies at Adelaide, Australia: Observations and a gravity wave-tidal interaction model, J. Atmos. Sci., 44, 605-619, 1987.

Fritts, D. C., Tsuda, T., VanZandt, T. E., Smith, S. A., Sato, T., Fukao, S., and Kato, S.: Studies of velocity fluctuations in the lower atmosphere using the MU radar, Part II: Momentum fluxes and energy densities, J. Atmos. Sci., 47, 51-66, 1990.

Kovalam, S., Vincent, R. A., and Love, P.: Gravity waves in the equatorial MLT region, J. Atmos. Sol. Terr. Phys., 68, 266-282, 2006.

Nakamura, T., Aono, T., Tsuda, T., Admiranto, A. G., Achmad, E., and Suranto: Mesospheric gravity waves over a tropical convective region observed by $\mathrm{OH}$ airglow imaging in Indonesia, Geophys. Res. Lett., 30(17), 1882, doi:10.1029/2003GL017619, 2003.

Nitta, T. and Sekine, S.: Diurnal variation of convective activity over the tropical western pacific, J. Met. Soc. Japan, 72(5), 627641, 1994.

Piani, C., Durran, D., Alexander, M. J., and Holton, J. R.: A numerical study of three diemnsional gravity waves triggered by deep tropical convection and their role in the dynamics of the QBO, J. Atmos. Sci., 57(22), 3689-3702, 2000.

Ratnam, M. V., Alexander, S. P., Kozu, T., and Tsuda, T.: Characteristics of gravity waves observed with intensive radiosonde campaign during November-December 2005 over western Sumatra, Earth Planets Space., 61, 983-993, 2009.

Renggono, F., Hashiguchi, H., Fukao, S., Yamanaka, M. D., Ogino, S.-Y., Okamoto, N., Murata, F., Sitorus, B. P., Kudsy, M., Kartasasmita, M., and Ibrahim, G.: Precipitating clouds observed by $1.3-\mathrm{GHz}$ boundary layer radars in equatorial Indonesia, Ann. Geophys., 19, 889-897, doi:10.5194/angeo-19-889-2001, 2001.

Sridharan, S. and Sathishkumar, S.: Seasonal and interannual variations of gravity wave activity in the low-latitude mesosphere and lower thermosphere over Tirunelveli $\left(8.7^{\circ} \mathrm{N}, 77.8^{\circ} \mathrm{E}\right)$, Ann. Geophys., 26, 3215-3223, doi:10.5194/angeo-26-3215-2008, 2008.

Taylor, M. J., Pautet, P.-D., Medeiros, A. F., Buriti, R., Fechine, J., 
Fritts, D. C., Vadas, S. L., Takahashi, H., and São Sabbas, F. T.: Characteristics of mesospheric gravity waves near the magnetic equator, Brazil, during the SpreadFEx campaign, Ann. Geophys., 27, 461-472, doi:10.5194/angeo-27-461-2009, 2009.

Tsuda, T., Nishida, M., Rocken, C., and Ware, R. H.: A global morphology of gravity wave activity in the stratosphere revealed by the GPS occultation data (GPS/MET), J. Geophys. Res. Lett., 105(D6), 7257-7273, 2000.
Vadas, S. L., Taylor, M. J., Pautet, P.-D., Stamus, P. A., Fritts, D. C., Liu, H.-L., São Sabbas, F. T., Rampinelli, V. T., Batista, P., and Takahashi, H.: Convection: the likely source of the medium-scale gravity waves observed in the $\mathrm{OH}$ airglow layer near Brasilia, Brazil, during the SpreadFEx campaign, Ann. Geophys., 27, 231-259, doi:10.5194/angeo-27-231-2009, 2009. 